\title{
Comparison of Noninvasive Ventilation by Sequential Use of Mask and Helmet versus Mask in Acute Exacerbation of Chronic Obstructive Pulmonary Disease: A Preliminary Study
}

\author{
Vittorio Antonaglia ${ }^{a}$ Massimo Ferluga ${ }^{a}$ Rossella Molino ${ }^{b} \quad$ Umberto Lucangelo $^{a}$ \\ Alberto Peratoner ${ }^{a} \quad$ Erik Roman-Pognuz ${ }^{a} \quad$ Loredana De Simoni $^{a}$ Walter A. Zin ${ }^{c}$ \\ Departments of a Perioperative Medicine, Intensive Care and Emergency, and ${ }^{\mathrm{b}}$ Emergency Medicine, \\ Cattinara Hospital, Trieste, Italy; ${ }^{C}$ Carlos Chagas Filho Institute of Biophysics, Federal University of Rio de Janeiro, \\ Rio de Janeiro, Brazil
}

\section{Key Words}

Acute respiratory failure $\cdot$ Facial mask $\cdot$ Helmet $\cdot$

Noninvasive ventilation $\cdot$ Pressure support ventilation

\begin{abstract}
Background: Noninvasive positive pressure ventilation (NPPV) using a face mask is the ventilatory mode of choice in selected patients experiencing acute exacerbation of chronic obstructive pulmonary disease (COPD). A high incidence of intolerance limits the use of this approach. Objective: To evaluate the sequential use of mask and helmet during NPPV in patients with severe exacerbation of COPD in order to reduce the intolerance to these devices. Methods: Fifty-three patients ventilated for the first $2 \mathrm{~h}$ with NPPV by mask were studied. If gas exchange and clinical status improved, they were randomized to continue on NPPV by mask or helmet. Physiological parameters were measured at admission, after the first $2 \mathrm{~h}$ on NPPV by mask, $4 \mathrm{~h}$ after randomization and at discharge. Need for intubation, ventilatory assistance, length of stay (LOS) and complications were recorded. $\boldsymbol{R e}$ sults: After the first $2 \mathrm{~h}$ of NPPV, gas exchange and clinical parameters improved in 40 patients. Four hours after randomization, $\mathrm{PaCO}_{2}$ was lower in the mask group than in the helmet group. Nine patients in the mask group and 2 in the helmet group failed NPPV, 8 and 1, respectively, owing to in-
\end{abstract}

tolerance. Time of noninvasive ventilation and LOS were lower in the mask than in the helmet group. Conclusions: In patients with acute exacerbation of COPD and undergoing NPPV, the sequential use of a mask and helmet diminished the incidence of failure. Under the present experimental conditions, the use of a helmet increased LOS and the duration of artificial ventilation.

Copyright $\odot 2011$ S. Karger AG, Basel

\section{Introduction}

Noninvasive positive pressure ventilation (NPPV) using a face mask can be considered the ventilatory mode of choice in selected patients experiencing exacerbation of chronic obstructive pulmonary disease (COPD) [1-8]. NPPV delivered by a helmet has recently been proposed as first-line intervention to reverse acute respiratory failure in a significant number of patients with COPD exacerbations, and overall, helmet-treated patients present better tolerance and fewer complications than those treated with a mask $[9,10]$. In these studies, the patients who failed NPPV delivered by helmet required intubation mainly during the first hours of treatment. Antonelli et al. [9] suggested that this finding was due to a less efficient inspiratory effort, particularly remarkable in the

\section{KARGER}

Fax +4161306 1234

E-Mail karger@karger.ch

www.karger.com
C 2011 S. Karger AG, Basel

0025-7931/11/0822-0148\$38.00/0

Accessible online at:

www.karger.com/res
Vittorio Antonaglia, MD

Dipartimento di Medicina Perioperatoria

Terapia Intensiva ed Emergenza, Ospedale di Cattinara

Strada di Fiume 447, IT-34149 Trieste (Italy)

Tel. +39040 399 4471, E-Mail v.antonaglia@libero.it 
first hours of acute exacerbation of COPD, caused by the intrinsic elastic characteristics of the helmet. Thus, they limited its use to less severe cases of respiratory failure. Moreover, in the studies assessing treatment with NPPV by mask $[6,9-12]$, many patients in whom gas exchange was improved required intubation later on due to intolerance.

We hypothesized that during the acute phase of respiratory failure in COPD patients, the increased ventilatory demand [13] could be initially matched by the face mask. In patients who responded to the mask, the initial partial improvement in gas exchange and appropriate gas flow delivery overwhelmed the respiratory drive; the subsequent need for comfort could be provided to a large extent by the helmet. Thus, each device could be better explored taking into consideration its intrinsic limitations and advantages, resulting in an improved overall outcome. For this purpose, a series of patients with severe exacerbation of COPD were ventilated with NPPV delivered by mask during the first $2 \mathrm{~h}$ of treatment. Those who demonstrated improved gas exchange and clinical status were randomly assigned to one of two groups; one group continued mask treatment, while the other underwent helmet therapy.

As primary end point, we assessed the feasibility of using 2 different NPPV devices sequentially in the same patient. Secondly, we investigated the clinical evolution of the 2 groups of COPD patients.

\section{Patients and Methods}

\section{Study Design}

Figure 1 presents the design of the study. Fifty-three consecutive adult patients admitted to the Intensive Care Unit (ICU) of Cattinara Hospital during 2007 with acute exacerbation of COPD were investigated in the semirecumbent position. The diagnosis of COPD was made according to clinical history, physical examination and chest radiography. Additional criteria for enrollment included an exacerbation of dyspnea lasting less than 2 weeks and at least 2 of the following: respiratory rate above $30 \mathrm{bpm}, \mathrm{PaO}_{2}$ below $45 \mathrm{~mm} \mathrm{Hg}$ and arterial $\mathrm{pH}$ below 7.35 after breathing under a fractional inspired oxygen tension $\left(\mathrm{FIO}_{2}\right)$ below 0.35 for at least $10 \mathrm{~min}$ [2]. Exclusion criteria were as follows: Glasgow Coma Scale below 8; failure of more than 2 additional organs; severe hemodynamic instability; electrocardiographic ischemia signs or ventricular arrhythmia, and cardiopulmonary resuscitation. The Acute Physiology and Chronic Health Evaluation II score was determined $24 \mathrm{~h}$ after admission.

As first-line treatment, all patients underwent NPPV by facial mask (FlexiFit ${ }^{\circledR}$ model HC431; Fisher \& Paykel Healthcare, Auckland, NZ); the mask dead space amounted to $160 \mathrm{ml}$, and its submentonian design allowed maximum stability and airtightness. The patients also received medical therapy (i.e. oxygen therapy, nebulized $\beta_{2}$-agonists, systemic corticosteroids, diuretics and antibiotics) as prescribed by their attending physician. A 7200 Puritan Bennett ventilator (Carlsbad, Calif., USA) delivered pressure support ventilation (PSV) triggered by flow-by with initial settings of $15-\mathrm{cm} \mathrm{H}_{2} \mathrm{O}$ inspiratory positive airway pressure and a positive end-expiratory pressure (PEEP) amounting to $5 \mathrm{~cm} \mathrm{H}_{2} \mathrm{O}$. The baseline PSV level was progressively raised in $2-\mathrm{cm} \mathrm{H}_{2} \mathrm{O}$ steps until the respiratory rate was less than $30 \mathrm{bpm}$, accessory muscle activity disappeared [14] and the patient was comfortable, thus resulting in improved patient-ventilator synchrony and minimization of mask leakage. The flow trigger was set at 3-5 liters/min with a baseline flow of $15-20$ liters $/ \mathrm{min}$. $\mathrm{FIO}_{2}$ was used to maintain peripheral oxygen saturation $\left(\mathrm{SpO}_{2}\right)$ at $>90 \%$. All patients were continuously monitored with electrocardiography and pulse oximetry; repeated measurements of arterial blood gases provided information to adjust the ventilatory settings.

\section{Methods}

We considered the initial $2 \mathrm{~h}$ under the mask as a screening period to detect responders and nonresponders to NPPV. The patients in whom dyspnea and $\mathrm{pH}$ persisted unchanged and those who refused to continue under NPPV despite improved gas exchange, no difficulty in managing secretions, improved dyspnea and disappearance of accessory muscle activity were intubated and, thus, excluded from the study. Another physician, unaware of the study, used computer software to randomly assign the remaining patients on a patient-by-patient basis to 2 groups of 20 patients each: (1) those undergoing NPPV by helmet and (2) those who would continue to use the same mask. In the patients randomized to the helmet group, the device was changed as follows. The procedure was clearly explained to the patients and performed by a trained nurse after a 5-min-long period of preoxygenation with $\mathrm{FIO}_{2}=1$. If a sudden drop in $\mathrm{SpO}_{2}$ was detected during the transition, NPPV by mask was immediately reapplied with a higher pressure support value, and intubation was performed if hypoxemia persisted. The duration of the entire procedure was recorded.

We used a helmet (CaStar; Starmed, Mirandola, Italy) provided with antiasphyxia safeguards. Its characteristics were identical to those previously reported $[9,10]$. During NPPV by helmet, inspiratory pressure was increased $(+20 \%)$ and finely tuned according to the patient-ventilator synchrony until the respiratory rate was less than $30 \mathrm{bpm}$, accessory muscle activity disappeared [14], the patient was comfortable and leakage was minimized.

During the first $24 \mathrm{~h}$, NPPV was delivered according to gas exchange, with patient-required intervals of spontaneous breathing (with oxygen supplementation and aerosol therapy). These intervals were not introduced before the first $4 \mathrm{~h}$ after randomization had passed. At this point, the physiological parameters were determined. The pauses were discontinued when $\mathrm{SpO}_{2}<90 \%$ developed.

On the second day, and henceforth, periods of NPPV were alternated with spontaneous breathing, the duration of which was determined by $\mathrm{SpO}_{2}$ and gas exchange. All patients underwent respiratory physiotherapy (chest clapping, mobilization and postural drainage, expiration with the glottis open in the lateral posture) [10]. Therapists were instructed to alert the physician whenever cardiorespiratory parameters changed more than 25\% compared to the baseline values, $\mathrm{SpO}_{2}$ was less than $85 \%$ and severe dyspnea developed. In such cases, the patients were returned to NPPV. 
Fig. 1. Study design. Fifty-three patients with severe exacerbation of COPD were initially ventilated with NPPV. After $2 \mathrm{~h}$ of ventilation, 13 of them had failed therapy, were intubated and excluded from the study. The remaining 40 patients were randomly divided into 2 groups of 20 patients each; 1 group was ventilated via a facial mask while a helmet was used in the other.

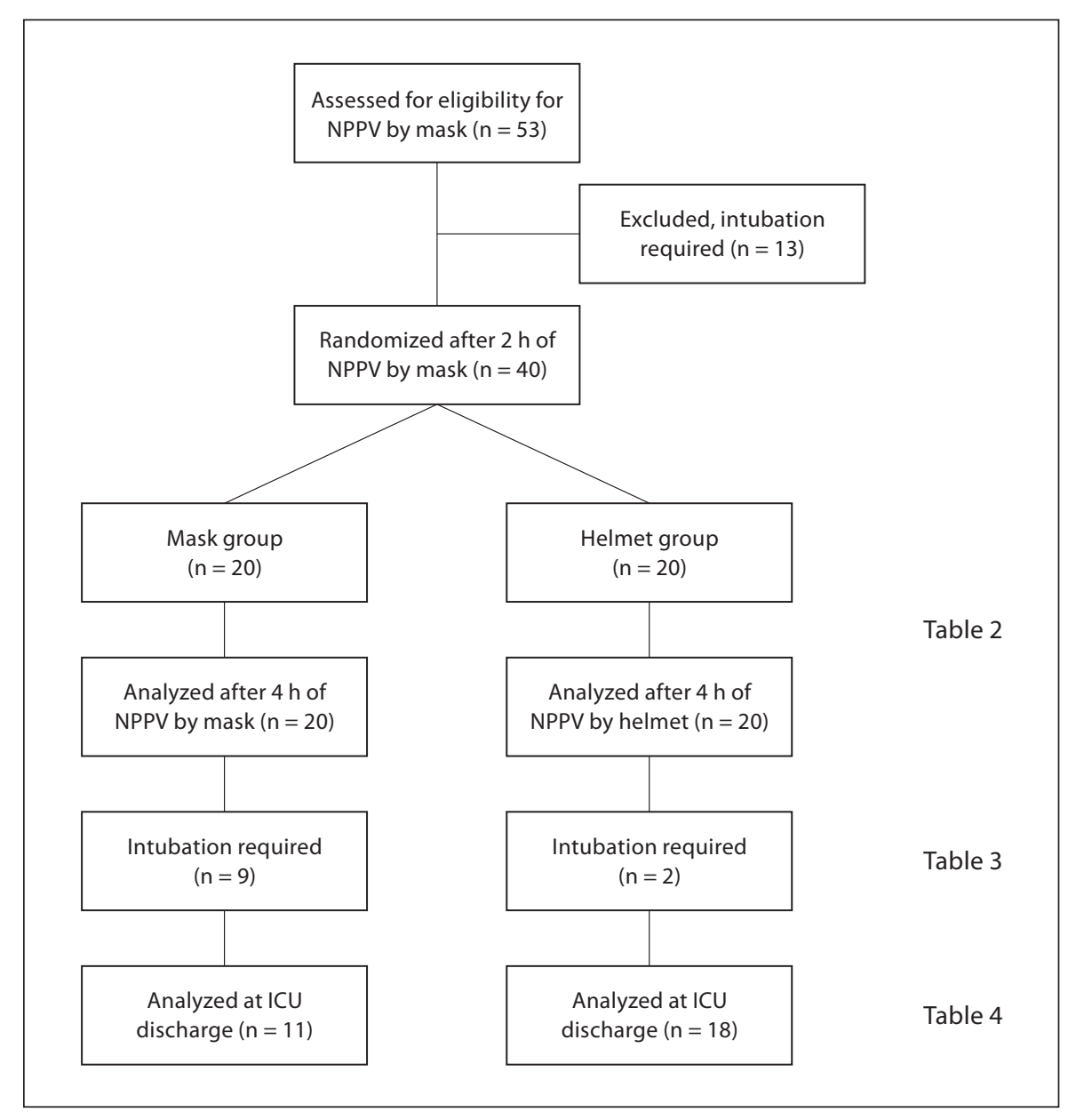

After the randomization, patients who developed respiratory arrest, bradycardia, hemodynamic instability, conditions requiring intubation either to protect the airways (coma or seizure disorders) or to manage copious tracheal secretions, or inability to tolerate the devices were intubated after determination of blood gas exchange. Device intolerance included compression by the device or straps, air leakage, noise, claustrophobia, dry mouth, throat or nose, headache, skin or eye soreness, patient-ventilator asynchrony and psychomotor agitation hindering nursing care and requiring deep sedation.

In both groups of patients we determined the duration of NPPV, length of stay (LOS) in the ICU, need for tracheostomy and ICU mortality. We also evaluated the presence of pneumonia (a new lung infiltrate on chest X-ray associated with at least 2 of the following conditions: fever, leukocytosis, purulent sputum in which Gram staining evidenced one or more types of bacteria) not present at admission, sepsis and metabolic complications $\left(\mathrm{Na}^{+}\right.$ $<120 \mathrm{mmol} / \mathrm{l}$ or $\mathrm{K}^{+}<3$ or $>6 \mathrm{mmol} / \mathrm{l}$, metabolic acidosis or alkalosis, or fasting hyperglycemia $>160 \mathrm{mg} / \mathrm{dl}$ ).

The criteria to discontinue NPPV were as follows: normal mental status, hemodynamic stability, respiratory rate below 25 bpm, absence of activation of accessory respiratory muscles and paradoxical abdominal motion, arterial $\mathrm{pH}>7.35, \mathrm{PaCO}_{2}<70$ mm Hg and $\mathrm{PaO}_{2}>55 \mathrm{~mm} \mathrm{Hg}$ under $\mathrm{FIO}_{2}>0.35$ without ventilatory support. Patients were discharged from the ICU when NPPV was switched to oxygen therapy with $\mathrm{FIO}_{2}<0.35$ for at least $24 \mathrm{~h}$ and the patients met the following criteria: hemodynamic stability, respiratory rate $<25 \mathrm{bpm}, \mathrm{pH}>7.35, \mathrm{PaO}_{2}>55 \mathrm{~mm} \mathrm{Hg}, \mathrm{PaCO}_{2}$ $<70 \mathrm{~mm} \mathrm{Hg}$, and absence of fever, leukocytosis, purulent sputum or metabolic complications. An independent clinical team not involved in the research protocol made the decision regarding discharge.

The study was approved by the local Ethics Committee, and informed consent was obtained from each individual or his/her next of kin.

\section{Analysis}

Normality of data distribution was appraised with the Kolmogorov-Smirnov test. Homoscedacity was tested with the Levene median test with Lilliefors correction. If both conditions were satisfied, Student's t test was used. When one of the aforementioned conditions was not satisfied, the Mann-Whitney test was used instead. The $\chi^{2}$ test (or Fisher's exact test when appropriate) was applied to categorical data. SigmaStat 3.11 statistical software (Systat Software, Point Richmond, Calif., USA) was used in all instances. The null hypothesis was rejected at $\alpha=0.05$. 
Table 1. Anthropometric and functional characteristics at admission in patients later divided into mask and helmet groups

\begin{tabular}{lccl}
\hline & Mask $(\mathrm{n}=20)$ & Helmet $(\mathrm{n}=20)$ & $\mathrm{p}$ \\
\hline Age, years & $71 \pm 7$ & $69 \pm 8$ & n.s. \\
Height, m & $1.68 \pm 0.16$ & $1.67 \pm 0.12$ & n.s. \\
Weight, kg & $69 \pm 8$ & $71 \pm 11$ & n.s. \\
$\mathrm{RR}, \mathrm{min}^{-1}$ & $32(29-34)$ & $33(30-35)$ & n.s. \\
$\mathrm{pH}$ & $7.20 \pm 0.06$ & $7.21 \pm 0.05$ & n.s. \\
$\mathrm{PaCO}_{2}, \mathrm{~mm} \mathrm{Hg}$ & $77 \pm 6.8$ & $79 \pm 7.2$ & n.s. \\
$\mathrm{PaO}_{2} / \mathrm{FIO}_{2}$ & $169 \pm 33.9$ & $175 \pm 28$ & n.s. \\
$\mathrm{MAP}_{\mathrm{mm} \mathrm{Hg}}$ & $92 \pm 8.4$ & $94 \pm 7.1$ & n.s. \\
$\mathrm{APACHE} \mathrm{II}$ & $23(20-27)$ & $22(20-26)$ & n.s. \\
\hline
\end{tabular}

Data are expressed as means \pm SD or medians (1st and 3rd quartiles). $\mathrm{RR}=$ Respiratory rate; $\mathrm{MAP}=$ mean arterial pressure; APACHE = Acute Physiology and Chronic Health Evaluation; n.s. = not significant.

\section{Results}

During the first $2 \mathrm{~h}$ under NPPV by mask, 13 patients required intubation and were thus excluded from the study.

Table 1 shows the anthropometric and functional characteristics of the COPD patients later divided into mask and helmet groups at admission to the ICU. No differences between the 2 groups were detected. Before randomization, both groups presented similar mean values of PSV and PEEP $\left(20.6 \pm 4.7\right.$ and $6.2 \pm 2.4 \mathrm{~cm} \mathrm{H}_{2} \mathrm{O}$, and $19.9 \pm 4.9$ and $6.1 \pm 2.5 \mathrm{~cm} \mathrm{H}_{2} \mathrm{O}$, respectively).

In the helmet group, the change of devices was well tolerated and no complications were reported. The mean time taken to change to the helmet was $3.6 \pm 0.8 \mathrm{~min}$.

Table 2 lists the physiological variables in both groups determined at the time of randomization and $4 \mathrm{~h}$ later. At the time of randomization, no difference was found between the groups, while $4 \mathrm{~h}$ later, the mask group presented lower $\mathrm{PaCO}_{2}$ than the helmet group.

Throughout ventilatory assistance, mean PSV was higher in the helmet patients than in the mask group $\left(24.2 \pm 4.4\right.$ and $20.3 \pm 4.9 \mathrm{~cm} \mathrm{H}_{2} \mathrm{O}$, respectively; $\mathrm{p}<$ 0.001 ), whereas no significant difference in PEEP was detected $\left(7.8 \pm 2.3\right.$ and $6.0 \pm 2.5 \mathrm{~cm} \mathrm{H}_{2} \mathrm{O}$, respectively).

Up to discharge, 9 and 2 patients in the mask and helmet groups, respectively, required intubation and mechanical ventilation owing to impaired gas exchange (1 patient in each group) and intolerance to the interface (8 and 1 patients, respectively; table 3). Many factors caused intolerance to the mask: dry mouth and throat (4 pa- tients), psychomotor agitation (3 patients), skin irritation and pain ( 3 patients) and claustrophobia (2 patients). A single patient showed intolerance to the helmet because of compression by the armpit braces. Gas exchange variables, mean arterial pressure, respiratory rate and the duration of NPPV in those patients of both groups who required intubation are also presented in table 3.

Table 4 lists the physiological variables of patients successfully treated with NPPV $(\mathrm{n}=29)$ at discharge from the ICU. No difference was detected between the experimental groups. Table 5 shows that intubation was required to a greater extent by patients in the mask group, but they were discharged with a shorter duration of ventilatory assistance and LOS in the ICU than the helmet group, while no differences were found in terms of complications.

Finally, 3 and 2 patients in the mask and helmet groups, respectively, had been previously admitted to the ICU. However, these admissions occurred at least 6 months before the present study was undertaken.

\section{Discussion}

The present investigation demonstrates the feasibility of the sequential use of mask and helmet to deliver NPPV in patients with severe exacerbation of COPD. Patients did not develop discomfort due to the change of device, and gas exchange was not compromised. This combination resulted in a better overall outcome, in terms of NPPV failure, in comparison with patients treated maintaining the same mask throughout the trial.

In patients requiring NPPV after extubation, a greater inspiratory muscle effort has been demonstrated in those using a helmet than in those ventilated by mask with similar PSV and PEEP [15]. This finding can be attributed to the partial dissipation of the inspiratory pressure by the compliant part of the helmet, which thwarts the patientmachine synchrony, and is in line with the higher $\mathrm{PaCO}_{2}$ in helmet patients in the present study (table 2) $[9,10]$. In this context, patient-machine synchrony represents an important factor in the successful use of NPPV to treat patients with severe exacerbation of COPD. A delay in pressurization of the helmet is not compatible with the high inspiratory drive generated by these patients, especially in the acute phase [16]. In contrast, such a time lag does not occur when a mask is used. Moreover, an adequate fast response linking inspiratory flow to the increased ventilatory demand can rapidly reduce the inspiratory drive, thus limiting the use of the helmet. 
Table 2. Physiological parameters at the time of randomization and $4 \mathrm{~h}$ later

\begin{tabular}{|c|c|c|c|c|}
\hline & \multicolumn{2}{|c|}{ At the time of randomization } & \multicolumn{2}{|c|}{$4 \mathrm{~h}$ after randomization } \\
\hline & $\operatorname{mask}(\mathrm{n}=20)$ & helmet $(\mathrm{n}=20)$ & $\operatorname{mask}(\mathrm{n}=20)$ & helmet $(n=20)$ \\
\hline $\mathrm{PaCO}_{2}, \mathrm{~mm} \mathrm{Hg}$ & $71.3 \pm 7.0$ & $72.2 \pm 7.5$ & $63.1 \pm 3.8$ & $69.6 \pm 4.1^{*}$ \\
\hline $\mathrm{PaO}_{2} / \mathrm{FIO}_{2}$ & $184 \pm 28$ & $184 \pm 17$ & $226 \pm 32$ & $237 \pm 29$ \\
\hline $\mathrm{MAP}, \mathrm{mm} \mathrm{Hg}$ & $96.5 \pm 8$ & $94.3 \pm 7$ & $89.5 \pm 6$ & $83 \pm 9$ \\
\hline
\end{tabular}
0.01 .

Data are expressed as means $\pm \mathrm{SD}$ or medians (1st and 3rd quartiles). MAP $=$ Mean arterial pressure; $\mathrm{RR}=$ respiratory rate. ${ }^{*} \mathrm{p}<$

Table 3. Gas exchange, arterial pressure, respiratory rate and duration of NPPV in patients who required intubation

\begin{tabular}{|c|c|c|c|c|c|c|c|}
\hline \multirow[t]{7}{*}{ Mask } & intolerance $(\mathrm{n}=8)$ & 7.28 & 69 & 198 & 98 & 32 & 8 \\
\hline & & 7.30 & 70 & 195 & 110 & 26 & 16 \\
\hline & & 7.22 & 68 & 225 & 62 & 10 & 12 \\
\hline & & 7.29 & 60 & 190 & 121 & 38 & 64 \\
\hline & & 7.26 & 69 & 325 & 60 & 13 & 35 \\
\hline & & 7.27 & 71 & 265 & 75 & 15 & 19 \\
\hline & impaired gas exchange $(\mathrm{n}=1)$ & 7.19 & 87 & 125 & 85 & 36 & 50 \\
\hline \multirow[t]{2}{*}{ Helmet } & intolerance $(\mathrm{n}=1)$ & 7.29 & 66 & 237 & 89 & 32 & 42 \\
\hline & impaired gas exchange $(\mathrm{n}=1)$ & 7.19 & 87 & 155 & 77 & 31 & 55 \\
\hline
\end{tabular}

$\mathrm{MAP}=$ Mean arterial pressure $\mathrm{RR}=$ respiratory rate.

Table 4. Physiological variables at discharge from ICU

\begin{tabular}{lccc}
\hline & Mask $(\mathrm{n}=11)$ & Helmet $(\mathrm{n}=18)$ & $\mathrm{p}$ \\
\hline $\mathrm{pH}$ & $7.38 \pm 0.02$ & $7.38 \pm 0.03$ & n.s. \\
$\mathrm{PaCO}_{2}, \mathrm{~mm} \mathrm{Hg}$ & $59 \pm 5.2$ & $62 \pm 6.0$ & n.s. \\
$\mathrm{PaO}_{2} / \mathrm{FIO}_{2}$ & $221 \pm 34.2$ & $232 \pm 14.8$ & n.s. \\
$\mathrm{MAP}_{\mathrm{mm}} \mathrm{Hg}$ & $83 \pm 3.4$ & $84 \pm 3$ & n.s. \\
$\mathrm{RR}, \mathrm{min}^{-1}$ & $24(24-27)$ & $23(22-24)$ & n.s. \\
\hline
\end{tabular}

Data are expressed as means $\pm \mathrm{SD}$ or medians (1st and 3rd quartiles). $\mathrm{MAP}=$ Mean arterial pressure; $\mathrm{RR}=$ respiratory rate; n.s. = not significant.
Table 5. Characteristics and outcome variables in patients with acute exacerbation of COPD

\begin{tabular}{lllc}
\hline & $\begin{array}{l}\text { Mask } \\
(\mathrm{n}=20)\end{array}$ & $\begin{array}{l}\text { Helmet } \\
(\mathrm{n}=20)\end{array}$ & $\mathrm{p}$ \\
\hline $\begin{array}{l}\text { Patients requiring intubation } \\
\quad \text { Impaired gas exchange }\end{array}$ & $9(45 \%)$ & $2(10 \%)$ & $<0.01$ \\
$\quad \begin{array}{l}\text { Intolerance } \\
\text { Ventilatory assistance in }\end{array}$ & 8 & 1 & \\
$\quad$ & 1 & \\
$\quad$ NPPV, h & $62(58-71)$ & $89(82-96)$ & $<0.01$ \\
$\begin{array}{l}\text { Metabolic complications } \\
\text { Sepsis and pneumonia }\end{array}$ & $7(6-8)$ & $10(8-11)$ & $<0.01$ \\
Tracheostomy & $3(15 \%)$ & $4(20 \%)$ & n.s. \\
\hline
\end{tabular}

Data are expressed as absolute values (percentage) or medians (1st and 3rd quartiles). n.s. = Not significant. 
We used NPPV by mask as a first approach, limiting to $2 \mathrm{~h}$ the period needed to establish whether the patients were responders to NPPV $[1,8]$. After this period, we assessed if maintenance of the same mask or transition to the helmet modified the outcome. During the first $2 \mathrm{~h}$ after admission, $25 \%$ of our initial 53 patients did not respond to NPPV and were excluded from the study. In our previous study, we reported a similar rate of NPPV failure using a mask in the first $2 \mathrm{~h}[10]$. In two studies [11, 12] that compared noninvasive ventilation as an alternative to conventional mechanical ventilation in patients with severe COPD exacerbation, higher incidences of failure were reported, but the average duration of NPPV before intubation was longer.

After randomization, 9 patients in the mask group required intubation, 8 due to intolerance to the device, despite the use of an advanced interface between patient and ventilator able to reduce skin damage [17]. Table 3 shows that in these patients, the decision to intubate was not affected by impaired gas exchange. Antonelli et al. [9] reported that $36 \%$ of patients failed NPPV due to intolerance to the mask, while in the studies where NPPV was proposed as an alternative to invasive mechanical ventilation, intolerance to the mask was responsible for $25 \%$ [11] and 37\% [12] of failures. The higher incidence of intolerance in the present investigation must be considered bearing in mind that 13 patients failed within $2 \mathrm{~h}$ of NPPV delivered by mask and were thereafter not included in the analysis. Moreover, in the present study, the use of NPPV by mask was prolonged because the exacerbation of COPD was more significant than in the study of Antonelli et al. [9] [median $62 \mathrm{~h}$ (range 58-71) vs. mean $30 \pm 21 \mathrm{~h}$ ]. In the helmet group, there was an overall failure rate of $10 \%$, as also reported by Antonelli et al. [9].

To our knowledge, there is no previous study in which a mask and subsequently a helmet were used to deliver NPPV in the treatment of acute bouts of COPD. The present study was not designed to compare the use of different types of mask in relation to the helmet; it is probable that different interfaces would yield diverse findings. Recently, Fraticelli et al. [18] suggested that interfaces could be interchangeable in clinical practice, provided that the ventilatory settings were adjusted. In the present investigation, a helmet was substituted for a mask in the helmet group, and the PSV and PEEP were arbitrarily increased by $20 \%$. As a result, the potential intolerance to the facial mask was minimized, and the percentage of patients who failed NPPV because of intolerance was smaller in the helmet than in the mask group.
Our data demonstrated that the use of two devices reduced the need for intubation (table 5). Conversely, this group presented longer use of NPPV and also increased LOS in the ICU than the mask patients (table 5). These findings could possibly be explained by the fact that the arbitrary $20 \%$ increase in pressure under PSV and PEEP in the helmet group might be insufficient to compensate for the energy dissipated against the helmet wall and to rapidly translate the pressure gradient. Indeed, it was demonstrated previously [15] that if helmet and mask are used with the same pressure settings, the former induces a greater inspiratory muscle effort that was, nevertheless, abolished by a $50 \%$ raise in both PSV and PEEP. Our investigation was performed before these findings were reported, and our data at $4 \mathrm{~h}$ after randomization are in line with the results of Vargas et al. [15] $\left(\mathrm{PaCO}_{2}\right.$ significantly lower in the mask group, $\mathrm{p}<0.01$ ).

The early phase of respiratory failure in COPD patients is characterized by moderate to severe hypoxemia and severe hypercapnia. NPPV delivered by mask adds a limited dead space, thus yielding an increment in oxygenation and carbon dioxide washout. The latter is not so effective when a helmet is used under similar PEEP and pressure support due to the different carbon dioxide kinetics that occur in a semiclosed environment [19]. The helmet group presented such behavior $4 \mathrm{~h}$ after randomization (table 2), which had disappeared at discharge from the ICU (table 4). The latter result was obtained because of a longer duration of ventilation and LOS (table 5). Presumably, a stronger PSV could reduce these effects; however, it could also induce a less tolerable environment for the patient. In this line, Vargas et al. [15] support the application of a higher PSV level. On the other hand, the early failure of NPPV by mask owing to intolerance ( 5 patients on the first day; table 3) contributed to the shorter duration of ventilatory assistance in the mask group. Moreover, in the mask patients successfully treated with NPPV, the better $\mathrm{CO}_{2}$ washout possibly determined the overall shorter duration of ventilatory treatment.

A complete assessment of respiratory physiological measurements, such as tidal volume or respiratory muscle effort, was not performed in our preliminary study. In addition, the sample size was limited to a small group of patients. Further studies, including sequential use of different interfaces delivering NPPV and titration of the applied pressure support, will be able to guarantee the best compromise between improvement in gas exchange and potential patient discomfort in order to reduce NPPV failure. 
In conclusion, in patients with acute exacerbation of COPD and under NPPV, the sequential use of a face mask and helmet diminished the rate of treatment failure. Under the present experimental conditions, the use of a helmet increased the duration of the artificial ventilation and also the LOS in the ICU.

\section{Acknowledgements}

Dr. W.A. Zin is a researcher for the Brazilian National Council for Scientific and Technological Development (CNPq/MCT), Brazil, and a visiting professor at the University School of Medicine, Trieste, Italy.

\section{References}

$>_{1}$ Bott J, Caroll MP, Conway JH Keilty SE, Ward EM, Brown AM, Paul EA, Elliott MW, Godfrey RC, Wedzicha JA: Randomized controlled trial of nasal ventilation in acute ventilatory failure due to chronic obstructive airways disease. Lancet 1993;341:1555-1557.

- Brochard L, Mancebo J, Wysocki M, Lofaso F, Conti G, Rauss A, Simonneau G, Benito S, Gasparetto A, Lemaire F: Non invasive ventilation for acute exacerbation of chronic obstructive pulmonary disease. N Engl J Med 1995;333:817-822.

- 3 Meduri GU, Turner RE, Abou-Shala N, Wunderink R, Tolley E: Noninvasive positive pressure ventilation via face mask: firstline intervention in patients with acute hypercapnic and hypoxemic respiratory failure. Chest 1996;109:179-193.

4 Hilbert G, Gruson D, Gbikpi-Benissan G, Cardinaud JP: Sequential use of noninvasive pressure support ventilation for acute exacerbation of COPD. Intensive Care Med 1997; 23:955-961.

5 Peter JV, Moran JL, Phillips-Hughes J, Warn $\mathrm{D}$ : Noninvasive ventilation in acute respiratory failure. A meta-analysis update. Crit Care Med 2002;30:555-562.

6 Lightowler JV, Wedzicha JA, Elliott MW, Ram FS: Noninvasive positive pressure ventilation to treat respiratory failure resulting from exacerbation of chronic obstructive pulmonary disease: Cochrane systematic review and meta-analysis. BMJ 2003;326:185190.
Kirakli C, Cerci T, Ucar ZZ, Erer OF, Bodur HA, Bilaceroglu S, Ozkan SA: Noninvasive assisted pressure-controlled ventilation: as effective as pressure support ventilation in chronic obstructive pulmonary disease? Respiration 2008;75:402-410.

8 International Consensus Conferences in Intensive Care Medicine. Noninvasive positive pressure ventilation in acute respiratory failure. Am J Respir Crit Care Med 2001;163: 283-291.

9 Antonelli M, Pennisi MA, Pelosi P, Gregoretti C, Squadrone V, Rocco M, Cecchini L, Chiumello D, Severgnini P, Proietti R, Navalesi $\mathrm{P}$, Conti G: Noninvasive positive pressure ventilation using a helmet in patients with acute exacerbation of chronic obstructive pulmonary disease. Anesthesiology 2004;100:16-24.

10 Antonaglia V, Lucangelo U, Zin WA, Peratoner A, De Simoni L, Capitanio G, Pascotto $S$, Gullo A: Intrapulmonary percussive ventilation improves the outcome of patients with acute exacerbation of chronic obstructive pulmonary disease using a helmet. Crit Care Med 2006;34:2940-2945.

11 Conti G, Antonelli M, Navalesi P, Rocco M, Bufi M, Spadetta G, Meduri GU: Noninvasive vs. conventional mechanical ventilation in patients with chronic obstructive pulmonary disease after failure of medical treatment in the ward: a randomized trial. Intensive Care Med 2002;28:1701-1707.

-12 Squadrone E, Frigerio P, Fogliati C, Gregoretti C, Conti G, Antonelli M, Costa R, Baiardi P, Navalesi P: Noninvasive versus invasive ventilation in COPD patients with severe acute respiratory failure deemed to require ventilatory assistance. Intensive Care Med 2004;30:1303-1310.
13 Krieger BP: Hyperinflation and intrinsic positive end-expiratory pressure: less room to breathe. Respiration 2009;77:344-350.

14 Brochard L, Harf A, Lorino H, Lemaire F: Inspiratory pressure support prevents diaphragmatic fatigue during weaning from mechanical ventilation. Am Rev Respir Dis 1989;139:513-521.

15 Vargas F, Thille A, Lyazidi A, Campo FR, Brochard L: Helmet with specific settings versus facemask for noninvasive ventilation. Crit Care Med 2009;37:2111-2113.

16 Racca F, Appendini L, Gregoretti C, Stra E, Patessio A, Donner CF, Ranieri VM: Effectiveness of mask and helmet interfaces to deliver noninvasive ventilation in a human model of resistive breathing. J Appl Physiol 2005;99:1262-1271.

17 Gregoretti C, Confalonieri M, Navalesi P, Squadrone V, Frigerio P, Beltrame F, Carbone G, Conti G, Gamna F, Nava S, Calderini E, Skrobik Y, Antonelli M: Evaluation of patient skin breakdown and comfort with a new face mask for non-invasive ventilation: a multi-center study. Intensive Care Med 2002;28:278-284.

18 Fraticelli AT, Lellouche F, L'her E, Taillé S, Mancebo J, Brochard L: Physiological effects of different interfaces during noninvasive ventilation for acute respiratory failure. Crit Care Med 2009;37:1146-1147.

19 Taccone P, Hess D, Caironi P, Bigatello LM: Continuous positive airway pressure delivered with a 'helmet': effects on carbon dioxide rebreathing. Crit Care Med 2004;32: 2090-2096. 